\title{
Analysis on the Localization Characteristics of Phonetic Teaching in Chinese Textbooks in Hungary and Italy
}

\author{
Zou Huihui (Corresponding author) \\ ELTE Confucius Institute at Eötvös Loránd Tudományegyetem University of Hungary
}

Liu Chang (Corresponding author)

Confucius Institute at Catholic University of the Sacred Heart

Chai Xiaoxiao (Corresponding author)

Confucius Institute at University of Malta

Received: July 28, 2021 Accepted: August 14, 2021 Published: August 16, 2021

doi:10.5296/ijele.v9i2.18944 URL: https://doi.org/10.5296/ijele.v9i2.18944

\begin{abstract}
In the context of the global Chinese language boom, Hungary and Italy are countries along the Belt and Road, and the Chinese language learning in the two countries is in the ascendant. However, the number of small language textbooks published on the market is scarce. For this reason, this article selects Hungarian Chinese Textbook and Italian Learn Chinese to analyze and compare the localization characteristics of phonetic teaching, hoping to provide concrete and substantive suggestions for future revision or compilation of targeted localized Chinese textbooks.
\end{abstract}

Keywords: Hungary, Italy, phonetic teaching, localization, Chinese textbooks, suggestions 


\section{Introduction}

The improvement of China's comprehensive strength and the increase of its influence in the world have promoted the rapid spread of Chinese language throughout the world. In the face of the growing popularity of Chinese overseas, Chinese teaching has always had the problem of lack of pertinence and practicality in teaching materials. The development trend of overseas Chinese textbooks has also shifted from the first general-purpose textbooks to more professional localized textbooks. In order to meet the needs of the new international Chinese teaching situation, after comparing and analyzing the highly used and popular Hungarian Chinese Textbook and Italian Learn Chinese in Hungary and Italy, we examined the similarities and differences of the content and arrangement of phonetic teaching of these two textbooks. Only by making up for the shortcomings can they improve their competitiveness in the construction of targeted and practical local Chinese teaching materials in Hungary, Italy, and other small languages; and also provide a reference for the construction of localized Chinese textbooks.

\section{Research on Localization of Chinese Teaching Materials}

"Localization" was first proposed in the economic field. It refers to the relevant adjustments and changes made by the subsidiaries of multinational companies to quickly adapt to the economic, social, and political environment of other countries in the process of their production and business activities.

\subsection{Definition of Localized Chinese Textbooks}

Localized textbooks are changes made in the principles of textbook compilation, content selection, and the use of teaching methods in order to adapt to the new teaching objects under the condition of the native language.

What is a localized textbook? Wu Yinghui (2013) proposed that "Localized Chinese textbook refers to a language textbook designed, compiled and produced as a foreign language or a second language based on the characteristics and requests of learners in a certain country or region to meet their learning needs." ${ }^{1}$

\subsection{Classification on Localized Teaching Materials}

\subsubsection{Localization of Language}

The new words of the two textbooks Hungarian Chinese Textbook and Italian Learning Chinese are all annotated in the students' mother tongue, so as grammar and Chinese culture. Take "I want to buy apples" in the 15th lesson of Hungarian Chinese Textbook Volume 1 as an example, the cultural knowledge of RMB and Chinese character "buy" are introduced in this part in Hungarian .

\footnotetext{
${ }^{1}$ Wu Yinghui (2013), Theoretical Discussion on the "Localization" and "Universal Applicability" of Teaching Materials for International Chinese Teaching "Application of Language and Characters" (3): 117-125
} 


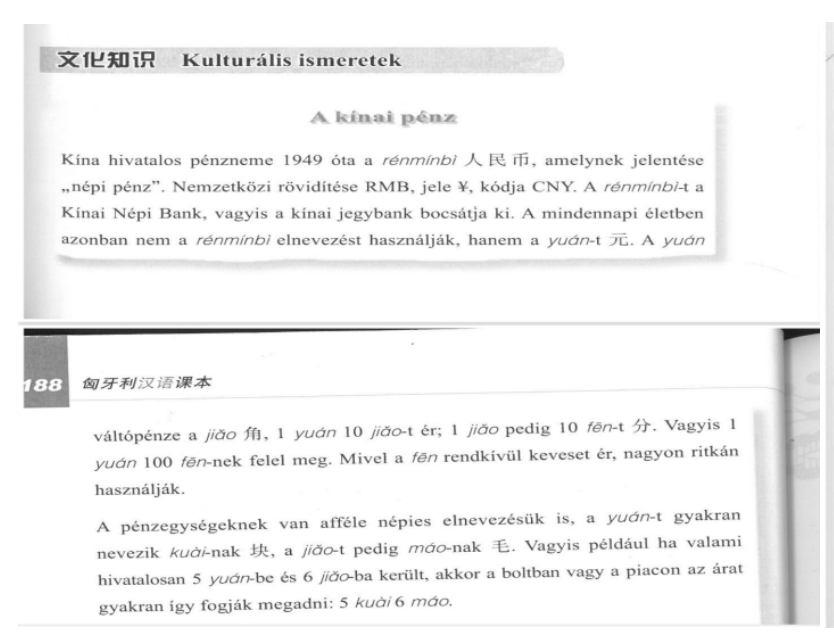

Figure 1. Introduction of cultural knowledge

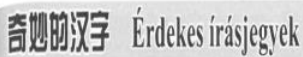

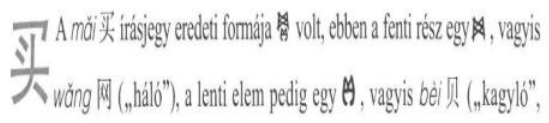

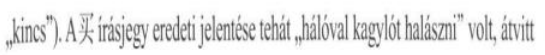

értelemben pedig - ebböl kiindulva - „megszerezai”'. Késöbb a $\$$, vagyis a

kagyllo egyfajta fizetöeszközzé valt, a 买 irásjegy jelentése pedio „pénzért ánut

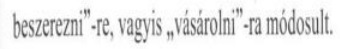

Figure 2. Introduction of Chinese character

\subsubsection{Localization of Language Content}

Both textbooks include the introduction of local culture, language comparison, teaching arrangements and practice methods, etc. to adjust the applicability of localization according to the characteristics of learners. Take Hungarian Chinese Textbook Volume 3, Lesson 12 "What do you think of Shandandan?" as an example. "Shandandan" is a small town in the suburbs of Budapest, because its Hungarian name szentendre is very similar to the Chinese "Shandandan", so the Chinese in Hungary call it Shandandan.

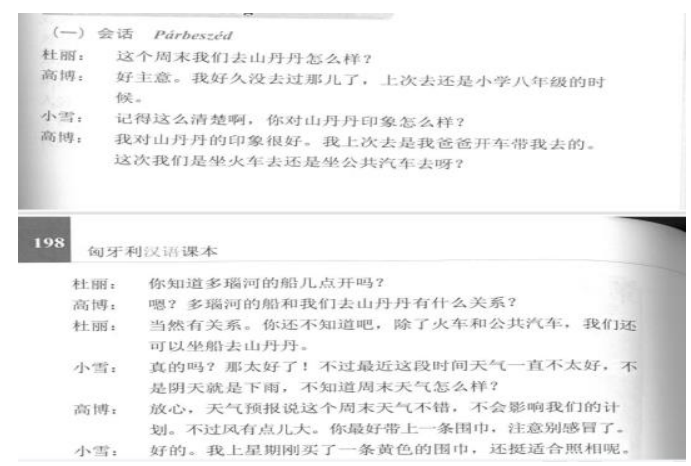

Figure 3. Hungarian Chinese Textbook-"What is your impression of Shandandan"

\section{Analysis of localized phonetic teaching features of Hungarian Chinese Textbook and Italians Learn Chinese}

\subsection{Compilation in Phonetics}

Both Hungarian Chinese Textbook and Italian Learn Chinese adopt the typesetting of "Chinese characters upper and lower Chinese phonics (Pinyin)". The difference is that the former pinyin and Chinese characters are separated, and the latter is integrated. Regardless of whether the Chinese characters and pinyin are separated, the two textbooks are intended to highlight the importance of Chinese characters. It is hoped that students can recognize and 
read Chinese characters as much as possible, instead of relying too much on pinyin. This is a foresight consideration. On the other hand, it may also be related to the traditions that Hungary and Italy that have always attached importance to Chinese character teaching.

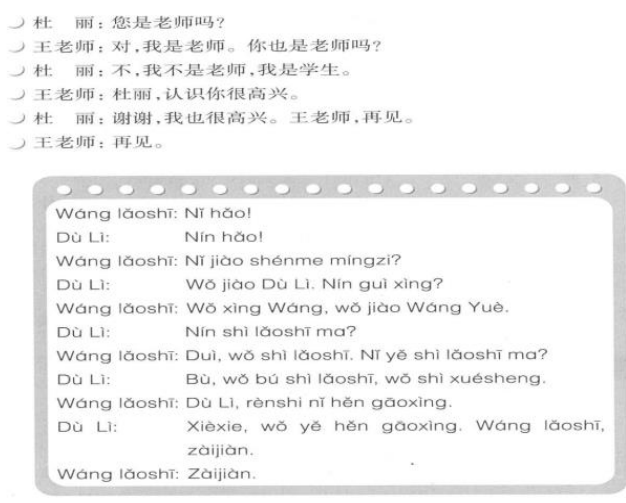

Figure 4. Hungarian Chinese Textbook 1

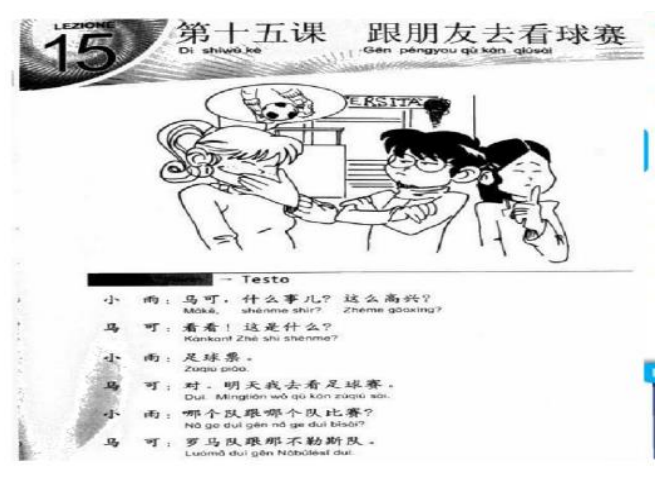

Figure 5. Italian Learns Chinese 1

For learners of any country, Chinese phonetics are the key points in learning, the foundation of the language, and the first part they come into contact with. Both sets of textbooks provide a basic introduction to Chinese phonetics.

In Italian Learn Chinese, the first to fourth lessons are "phonetics \& Chinese characters", which systematically explain the Chinese phonics. After the four lessons, there is also a table of Chinese consonants and vowels. In Hungarian Chinese Textbook, Lessons 1-5 are: "phonetics \& Chinese characters", which systematically explain Chinese phonics as well. In order to reduce the burden of students' learning, the content is divided into five lessons. At the end of each lesson, like Italian Learn Chinese, a table of Chinese consonants and vowels is attached.

Table 1. The phonetic content of Italian Learns Chinese

\begin{tabular}{|c|}
\hline Lesson 1: b, p, m, f, d, t, n, l/ a, o, e, i, u, ü; tone \\
\hline $\begin{array}{l}\text { Lesson 2: g, k, h, / ai, ei, ao, ou, an, en, in, ang, eng, ing, ong; tone change rules of the third-tone, } \\
\text { half tones, neutral tone }\end{array}$ \\
\hline $\begin{array}{l}\text { Lesson 3: j, q, x, z, c, s / ian, iao, iang, iong, ia, ie, iu(iou) üan, ün, üe; tone change rules of } \\
\text { "one" and "no" }\end{array}$ \\
\hline Lesson 4: zh, ch, sh, r / er, ua, uo, uai, ui(uei), uan, un(uen) \\
\hline
\end{tabular}

Table 2. The phonetic content of Hungarian Chinese Textbook

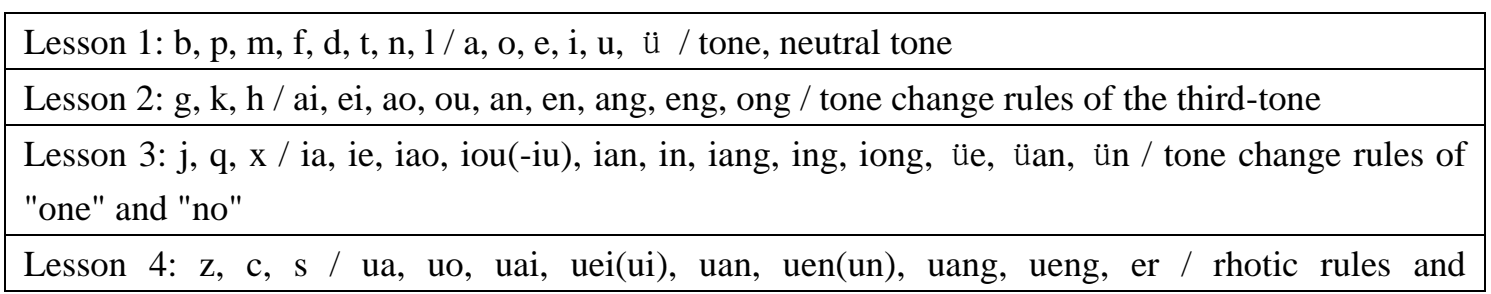


syllable-dividing mark

Lesson 5: zh, ch, sh, r

Since the phonetic parts of Italian Learning Chinese and Hungarian Chinese Textbook respectively introduced the localized characteristics in detail, the article mainly analyzed the phonetic parts of the two textbooks.

\subsubsection{Compilation \& Teaching on Consonant}

As a student's mother tongue, Italian will definitely transfer students' Chinese phonetic learning. The result of the transfer may have a promoting effect (positive transfer) or an obstructive effect (negative transfer). The promotion effect is manifested in the pronunciation similarities between Italian and Chinese consonant, such as "m, f, n, l, s", etc., which is easy for students to grasp. The hindrance is manifested in that the pronunciation of some Italian consonants are related to but different from Chinese pronunciation. For example, There are voiceless and voiced consonants in Italian, but there is no aspirated and non-aspirated consonants. Therefore, The pronunciation of consonants " $b, \mathrm{p}, \mathrm{d}, \mathrm{t}, \mathrm{g}, \mathrm{k}$ " are easily affected by the mother tongue.

There are 14 vowels and 30 consonants in Hungarian. Most of the phonemes are pronounced similar to those of Chinese phonemes. According to the actual teaching situation, the author shows the pronunciation of the consonants of Hungarian students as follows: The easiest and most standard consonants are "f, l, h, c, ch, s, sh, z, zh". The pronunciations of these consonants are exactly the same or almost the same as the consonants in Hungarian. For example, "f, 1, h" are exactly the same, and "c-c, ch-cs, s-sz, sh-s, z-zh" have a certain correspondence between Chinese and Hungarian. Therefore, students can master the pronunciation of these consonants with a little guidance. Next are the three aspirated sounds of "p, t, k"; followed by "b, d, g, m, n". These sounds are similar to the Hungarian"b, d, g, m, n", but students are prone to over-voicing, so as long as the learners pay enough attention, it is also not difficult to master.

However, the pronunciation of some Chinese consonants is completely different from Italian. For example, "j, q, x, z, c" are pronounced in Italian as [i] [k] [ks] [ts,dz] [k,t $\left.\int\right]$. Therefore, the textbook shows some examples of similar pronunciation in Italian to help learners master the pronunciation of these consonants, such as: "j" is similar to "ginnasta", "q" is similar to "città", "z" is similar to "zero", and "x" is similar to "ascia". At the same time, the textbook specifically points out the difficult points of pronunciation " $\mathrm{x}$ " and "c". It is necessary to pay attention to the aspiration sound and the position of the tongue. In addition, for some sounds that are not in Italian at all, such as "zh, ch, sh", the textbook also helps learners pronounce sounds by listing similar sounds in Italian, such as: "zh" is close to "giugno", "ch" is close to "ciao", and "sh" is close to "pascere". While " $\mathrm{r}$ " is a alveolar trill in Italian, the textbook uses the English word "road" as an example.

"r" is also a alveolar trill in Hungarian. Students are prone to the negative transfer of their 
mother tongue when pronouncing them, but if you practice more words or sentences with "r", students can still overcome the differences. The difficulty of Hungarian students in the consonants learning is the same as that of students from many European countries, which is the pronunciation of "j, q, x". "j" has the same letter in Hungarian, but its pronunciation is similar to Chinese "y". Therefore, when reading "jun", students can easily pronounce "yun".

"q" is the most difficult consonant for Hungarian students. In the process of learning , teachers use "i" to read "qi" and constantly practice the number "seven", but when "q" and "ü" are spelled out together, students will get into trouble again, always pronounce "ï" into "u". For the pronunciation of "x", students can easily confuse it with "s". When students pronounce "xiōng yá li", although teachers often correct them, they still pronounce it as "siōng yá lì" and read "bù dá pèi sī" as "bù dá pèi xī". When learners encounter obstacles in learning a language, they can temporarily slow down and learn other simple parts first, but they can't escape the difficulties. In addition to occasional corrections, the author regularly conducts "ask and answer" training with students and between students, such as "What's the date today(Jīntiān shì jǐ hào)?" "What day is it today(Jīntiān xīngqī jǐ)?" "What day is it tomorrow(Míngtiān shì jǐ hào)?" "Today is ...(Jīntiān xīngqī...)". Exercises contain "j, q, x" allow students to bravely challenge their pronunciation obstacles.

The textbook Italian Learning Chinese reminds this in the first lesson and guides students to correctly understand and pronounce aspirated and non-aspirated sounds through illustrations .

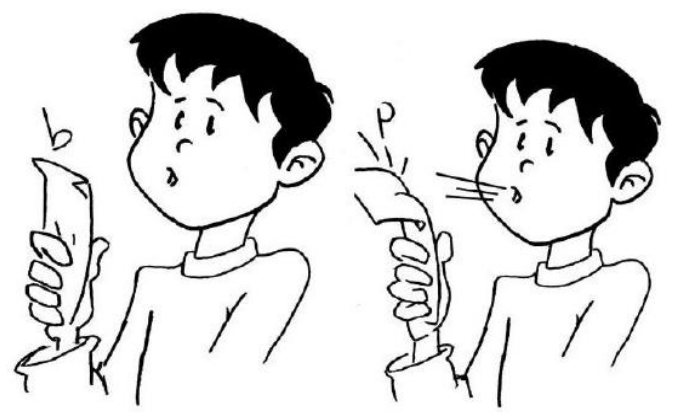

Figure 6. How to pronounce aspirated and non-aspirated sounds

\subsubsection{Compilation \& Teaching on Vowels}

Among the six single vowels in Chinese, the pronunciation and writing of "a, i, u" are the same as in Italian. It should be noted that the pronunciation of "e" in Italian is $[e, \varepsilon]$, while $\ddot{u}$ does not exist in Italian. Italian Learn Chinese only mentions that these single vowels are similar to the vowels in Italian, and learners need to pay attention to the pronunciation of "e" and "ï". Although the vowel "e" does not have a corresponding pronunciation in Italian, it is similar to "early" in English. The vowel "ü" is similar to the French "u", and the textbook also introduces the pronunciation skills of "ï", which is to pronounce the "i" sound first and then gradually round the lips. Out of consideration for Italian students learning English and French more, the pronunciation comparison makes it easier for students to master some pronunciations that do not exist in Italian. In addition, for Italian students, the back nasal vowel "ng" is also prone to pronunciation errors. The textbook specifically pointed out that 


\section{Ml Macrothink}

the final sound " $\mathrm{g}$ " is silent, and the pronunciation of " $a$ " in the compound vowel "ian" is similar to the pronunciation of "è" $[\varepsilon]$ in Italian.

In the pronunciation of vowels in Hungarian, middle-aged and elderly students are prone to pronounce "ê" when they pronounce "e". Because there are two pronunciations of "e" in Hungarian: one is "ê" (similar to the pronunciation of Chinese), and the other is "é" (between "i" and "ei"). Since most of the elder Hungarian students have not studied English before, teachers cannot explain to the students that the Chinese "e" is similar to the English [ə]. The front and back nasal vowels are also parts that are prone to errors, but through a lot of vowel recognition exercises and sentence exercises, students can also pronounce relatively standard pronunciation.

\subsubsection{Compilation \& Teaching on Tone}

Italian Learns Chinese in the first lesson spends a lot of effort to explain the importance of tones in Chinese. Take the four tones of "ma" as an example, and compare it with the difference in tones of "no" of different sentences in Italian. ${ }^{2}$ The comparison shows that Chinese tones play an important role in Chinese semantics. At the same time, the Chinese 5-level system is displayed to help students determine the pitch of the four tones, and the characteristics of Chinese tones are pointed out using "ma" and "ba" as examples.

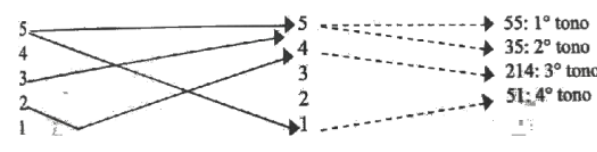

Figure 7. Chinese 5-level system

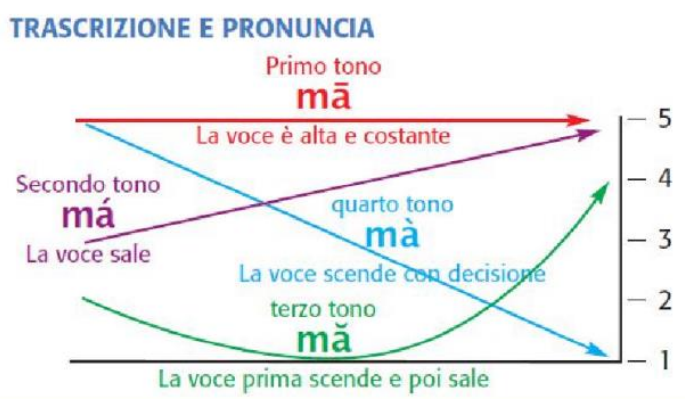

Figure 8. "Ma" in Chinese 5-level system

Hungarian is a language that has no word tones but sentence tones. The same sentence with different tones will express different meanings, for example: (te) Kínai vagy? (Use falling tones at the beginning and end of the sentence and a rising tone in the middle) means "Are you Chinese?", and (te) Kínai vagy. (The whole sentence uses falling tone) means "You are Chinese." Therefore, the distinction between sentences is: question sentences use rising tones in the middle of the sentence, falling tones used at the beginning and end of sentences, and falling tones for the whole sentence in declarative sentences.

\footnotetext{
${ }^{2}$ In Italian, The word "no" has different tones in different sentences such as imperative sentences for rejection and interrogative sentences with affirmative answers.
} 


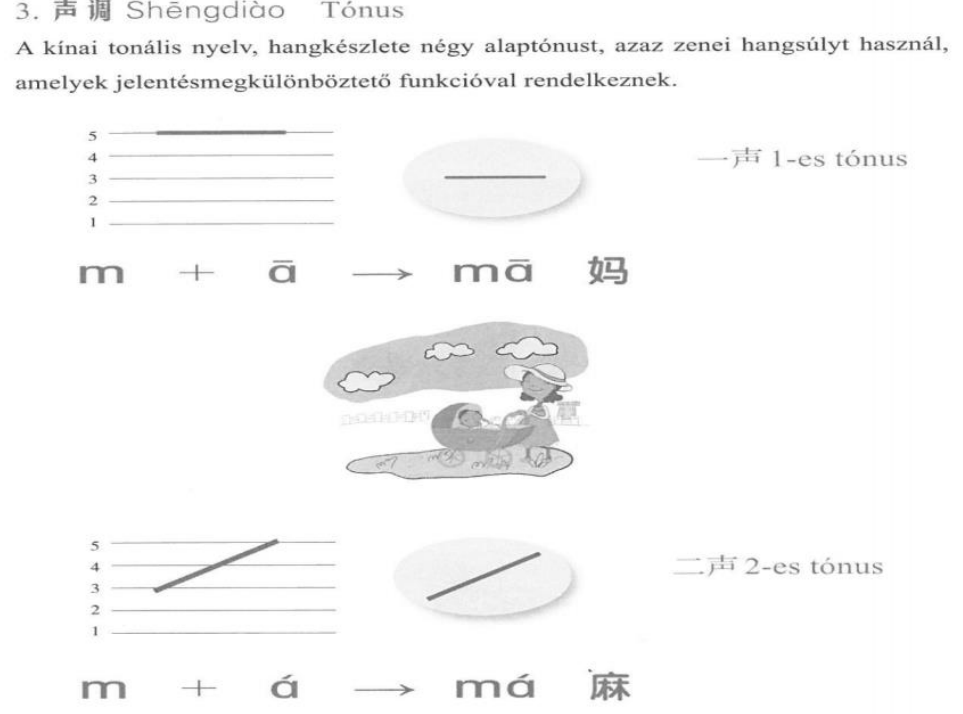

Figure 9. Tone Map of "Hungarian Chinese Textbook"-Lesson 1

Compared with the theory and professionalism of Italian Learns Chinese in the tones compilation, Hungarian Chinese Textbook is more suitable and clear for beginners of Chinese language learners.

In addition, because of the lack of tones in Hungarian, the textbook adds tone practices, "one" and "no" tone practices, and neutral tone exercises in this section. The exercises are distributed in all the 20 lessons in the first volume. Students can practice their weak parts from time to time.

\section{Suggestions on the Localization of Language Elements}

\subsection{Increase the Chinese-Hungarian Pronunciation Comparison, Highlight Key Points}

Most of the consonants in Hungarian pronunciation are similar to Chinese consonants, and it is easy for students to master similar pronunciations. In the process of learning, students can easily grasp these sounds with a little comparison. When the textbooks are revised later, these similarities can be pointed out to reduce students' psychological burden and study pressure.

For Hungarian students, "j, q, x" are quite difficult to pronounce correctly, especially "j". Because the pronunciation of " $\mathrm{j}$ " in Hungarian is similar to "y" in Chinese, and the negative transfer of mother tongue makes it easy for students to make mistakes when syllables related to " $\mathrm{j} "$ are pronounced. The textbooks were compiled as the phonetic sequence according to the Chinese Phonetics Plan with no key emphasis or targeted training. Therefore, the setting of phonetic explanation and practice should focus on practicing the phonemes that students are generally prone to error. 
4.2 Reduce the Professional Explanation of the Phonetic Part and Use a More Intuitive and Concise Method

Italian Learning Chinese should display the Chinese phonetics knowledge in a tabular format rather than explain it in long professional terms. Phonetic knowledge should be arranged in order of increasing difficulty, and a table of Chinese consonants and vowels can be added. Tone change rules for the third-tone, "one" and "no" are still necessary, but there is no need to explain too much theoretical basis. The corresponding exercises should be designed to be more targeted.

In addition, the influence of Italian on Chinese should not be ignored. The pronunciation characteristics of Italian should be combined to strengthen the positive transfer effect to Chinese pronunciation through comparison, so as to help learners master the pronunciation as soon as possible.

\section{Conclusion}

The localization of Chinese teaching materials is an inevitable choice for the development of Chinese promotion (Zhang Xiaotong, 2013). ${ }^{3}$ From the perspective of the localization characteristics of the textbook, this article analyzes and compares the localization factors of the phonetic teaching of the Hungarian Chinese Textbook and Italian Learns Chinese. We noticed that the phonetic knowledge of Hungarian Chinese Textbook is not focused, and Italian Learns Chinese is too professional and not intuitive enough. Suggestions are also given to the inadequacies in the compilation of localized phonetic teaching of teaching materials. In order to better solve the problem of compiling localized textbooks, it is necessary to analyze and sort out the textbooks in more detail, summarize the experience, and especially highlight the pertinence of localized textbooks. The ultimate goal of the localization of Chinese textbooks is to introduce Chinese language to the world. I believe that in the future there will be a large number of localized textbooks with their own characteristics, pertinence, and applicability, and are welcomed by local users in various countries.

\section{References}

Chen Fu. (2014). How to make overseas Chinese textbooks more country-specific: Taking the compilation of American AP Chinese textbooks as an example[J]. Journal of Yunnan Normal University (Teaching and Research on Chinese as a Foreign Language Edition), (2). https://doi.org/10.16802/j.cnki.ynsddw.2014.02.002

Hu Mingyang. (1999). Compilation of basic textbooks for teaching Chinese as a foreign language [J]. Language Teaching and Research, (1).

https://doi.org/CNKI:SUN:YYJX.0.1999-01-000

\footnotetext{
3 Zhang Xiaotong: "Thoughts and Suggestions on the Localization of Chinese Textbooks", "Journal of Chinese Literature", No. 22, 2013.
} 
Jiang Wenyan, Harmar Imre. (2011). Hungarian Chinese Textbook Volume One. Rector KFT, Budapest.

Li Xuemei. (2010). Thoughts on the compilation of Italian localized Chinese textbooks[J]. Overseas Chinese Education, (3): 31-36.

https://doi.org/10.14095/j.cnki.oce.2010.03.005

Liang Dongmei. (2008). Italian Learns Chinese" and its enlightenment on the compilation of Chinese language textbooks[J]. International Chinese Language Teaching Trends and Research, (4): 69-75. https://doi.org/CNKI:SUN:GHJY.0.2008-04-011

Wang Juan. (2011). Research on the national textbook "Hungarian Chinese Textbook". Master's degree Thesis. Beijing Foreign Studies University.

https://doi.org/CNKI:SUN:GHJY.0.2012-01-034

Wu Yinghui. (2013). Theoretical Discussion on the "Localization" and "Universal Applicability" of International Chinese Teaching Textbook. Language and Written Application, (3): 117-125. https://doi.org/10.16499/j.cnki.1003-5397.2013.03.019

Zhang Xiaotong. (2013). Thoughts and Suggestions on the Localization of Chinese Teaching Materials. Journal of Chinese Language and Literature, No. 22, 2013. https://doi.org/CNKI:SUN:YWXK.0.2013-22-059

Zhou Xiaobing, Chen Nan. (2013). "One Edition, Many Books" and the localization of overseas teaching materials. Teaching Chinese in the World, (2), 268-277. https://doi.org/10.13724/j.cnki.ctiw.2013.02.012

\section{Copyright Disclaimer}

Copyright for this article is retained by the author(s), with first publication rights granted to the journal.

This is an open-access article distributed under the terms and conditions of the Creative Commons Attribution license (http://creativecommons.org/licenses/by/4.0/). 